\title{
THE DEVELOPMENT OF RESISTANT PASTURE AND METHODS OF PASTURE MANAGEMENT FOR GRASS GRUB CONTROL
}

\author{
W. M. Kain and D. S. Atrinson \\ Insect Control Section, Ministry of Agriculture and Fisheries, \\ Palmerston North
}

\section{Abstract}

Studies of the plant-insect relationship of grass grub larvae have highlighted the sensitivity of this insect to changes in the botanical composition of existing pastures, the effect of resistant plants sown as pure species or in mixtures wtih susceptible species, and the intensity of defoliation 1 through the summer months. From these findings it is concluded that agronomic practices offer considerable scope as a component of a pest management programme for grass grub control.

\section{INTRODUCTION}

The FaILURe of exotic biotic agents (Given, 1967), as well as alternative insecticides to DDT, to provide acceptable control of grass grub populations has highlighted the fact that grass grub (Costelytra zealandica), like many insect pests elsewhere in the world, cannot be satisfactorily controlled solely with insecticides, or for that matter, by any other one-component control system.

It is this predicament that has focused attention on the feasibility of controlling grass grub through pest management. Simply put, pest management is the "integration of individual control methods into a harmonized system designed to control pests at levels below that at which they cause harm" (Anon., 1969). The successful development of pest management programmes must rest on firm ecological principles.

Long-term ecological studies of grass grub populations conducted over the past eight years at the Takapau research farm in central Hawkes Bay have shown that natural populations of grass grub are regulated by intraspecific competition in. the form of mortality arising from larval combat, and fluctuate in response to low soil moisture levels in summer and high soil moisture levels in spring (Kain, 1975). Protozoan pathogens may also be important in regulating grass grub populations, particularly in times of food stress (Miln and Kain, unpubl.). The severity 
of combat mortality is governed by weather which affects both the quantity and the quality of plant food available to the larvae. These factors influence both larval movement and the duration of larval feeding and therefore set the density threshold and period over which combat mortality occurs (Kain, 1975).

In view of the importance of host plants in regulating grass grub populations, the role of plant resistance and pasture management as possible components of control programmes for grass grub was investigated.

Resistant plants can be defined as plants which, are inherently less damaged or less infested by a pest relative to other plants under comparable environmental conditions in the field (Painter, 1951). Plant resistance is due to the expression in varying degrees of one or a number of components, namely, non-preference, antibiosis, and tolerance. These have been reviewed by Pottinger (1975).

Since New Zealand pastures may be defined as a dynamic and competitive association of plants, the seasoaal balance of which is maintained by the grazing animal, the performance of grass grub larvae on single plant species (e.g., Farrell and Sweney, 1972, 1974a, b) is only the first step in developing resistant pastures. The requirement, then, is for information on how different stages of grass grub perform on different mixtures of resistant and susceptible plants.

In order to understand the plant-insect relationship pertaining to insect feeding, it is necessary to have some appreciation of the mechanisms involved. Insect feeding usually involves the following sequence of events: host recognition and orientation, initiation of feeding, and maintenance of feeding. Each event is triggered by tactile, visual or chemical stimuli usually emanating from the plant (Beck, 1965). In Beck's classification, the orientation of locomotory activity to or away from the plant is governed by attractants or repellents, the loss of locomotory activity near the plant by arrestants, the induction or prevention of biting by incitants or suppressants, and the maintenance or prevention of feeding by stimulants or deterrents. The performance of larvae fed mixtures of plants will depend on the relative abilities.04 the roots of the different plant species to attract and arrest larval movement and thus aggregate larvae about them, the amount of root ingested and the food value of the roots.

The object of this paper is to give a resume of studies conducted to assess the feasibility of developing worthwhle resistant pastures with existing cultivars, and pasture management prac- 
tices for grass grub control. The more technical aspects of this work will be published elsewhere.

\section{CHARACTERISTICS OF LARVAL-PLANT RELATIONSHIP}

In terms of population density and larval growth, natural, populations of grass grub appear to be extremely sensitive to changes in the botanical composition of existing pastures. This sensitivity changes with different stages in the insect's life cycle. Of the species commonly found in pasture, the trifoliate legumes, particularly white clover, are extremely susceptible to grass grub compared with the grasses. Over the early larval instars, a reduction or elimination cf white clover has been shown to cause marked declines in grass grub populations.

Field studies have revealed the resistance of two additional grasses, Phalaris tubcrosa and Holcus lanatus, species which had escaped recognition in the controlled short-term studies conducted by Farrell and Sweney (1974a) and confirmed, in terms of bath larval growth and population density, the resistance of Lotus pedunculatus and lucerne, previously recorded in the laboratory by Farrell and Sweney (1974b), and in the case of lucerne, in the field by Kain and Atkinson (1970).

The performance and behaviour of grass grub populations, both in the laboratory and in the field under well balanced legumegrass mixtures, follows that found under the pure legume, irrespective of whether the legume in the mixture is resistant or susceptible.

This phenomenon results from the greater ability of legumes, relative to grasses, to aggregate grass grub, about their roots. Sutherland and Hillier (1974) found that grass grubs were more attracted to legumes, but their experiments did not study aggregation, which includes both the attraction and arrestance of larval movement.

Given the relative abilities of plants to aggregate grass grub about their roots and the densities supported by pure-species field plots, the likely outcome of mixing two species in the field can be predicted with an encouraging degree of accuracy, provided the species compositions of the mixtures are known.

Close positive linear relationships were found to exist between population density and larval weight during the summer and autumn when the larvae are most actively growing. Thereafter, this relationship was not significant, suggesting that liveweight gain is only critical in terms of survival below a certain weight 
and/or stage in development. The liveweight range in which it is possible to affect grass grub density by influencing larval growth through pasture management has been estimated from field experiments. Small plot trials have demonstrated that the intensity of defoliation of grass grub infested pastures over the summer and autumn can substantially alter the severity and pattern of larval mortality.

\section{DISCUSSION}

The information these studies have provided is vital in predicting the outcome of different pasture systems on grass grub populations. The manner in which resistant species can profitably be used in pasture systems will, of course, depend on the insectplant relationship and the agronomic capabilities of the resistant species.

Although pure stands of resistant plants such as lucerne offer scope as special-purpose pastures for controlling grass grub in flat areas, it is the hill country, where lucerne establishment is difficult, which poses the biggest grass grub control problem. This is due, in part, to the more marginal nature of farming in these areas and the physical problem of accurately distributing insecticide (Kain and Crabtree, 1972). The rapid spread of white-fringed weevil and lucerne diseases throughout the North Island may limit the use of lucerne in many areas, while the restricted seasonal production of pure species pastures limits their use within a farming system.

The maintenance of lotus, even at low levels, with grasses and white clover has been shown to effect a large decline in grass grub populations disproportionate to its occurrence. Observations made during these studies and backed by those from hill country where grass grub is a problem and where lotus usually occurs as a minor component of the sward has shown that as grass grub populations build up the more competitive ability of grass grubsusceptible dominant species, such as white clover, is reduced. In response to this, the lotus content of the pasture increases and grass grub populations collapse. In the absence of grass grub damage, however, the competitive ability of susceptible plants is restored and lotus reverts to a minor component. This "autocidal" control of grass grub through a grass grub-induced shift in the botanical composition suggests that it may be possible to achieve the same result earlier by grazing management or herbicidal manipulation and therefore minimize losses in production associated with grass grub damage. 
The management of trifoliate clovers in the pasture, particularly over the early larval instars in late summer, can have a major influence on grass grub populations. More detailed work on the clover content-population density relationship over this critical period is required to assess the worth of reducing clovers to control grass grub, or using annual clovers which seed and die or can be herbicidally eliminated before late summer. The use of grazing frequency and intensity to increase mortality also requites more detailed evaluation as a practical control method for grass grub.

As the plant-insect relationship of grass grub for both the new and commonly occurring pasture plants becomes better understood, agronomic methods for grass grub control can become more objectively based. For example, recent laboratory feeding studies on the common, pasture weed sheep's sorrel (Rumex acetosella) have revealed that this plant is as susceptible to grass grub as white clover and as a result will sustain extremely high grass grub populations. Therefore, attempts to control grass grub by agronomic methods in sorrel-infested areas must take this factor into account.

These preliminary studies suggest that from an entomological view point it is possible to control grass grub, populations by agronomic means. However, the agronomic consequences of this in terms of pasture productivity requires examination.

\section{REFERENCES}

Anon., 1969. Principles of Plant and Animal Pest Control. Vol. 3. Insect Pest Management and Control. National Academy of Sciences, Washington, D.C.

Beck, S. D., 1965. Resistance of plants to insects. A. Rev. Ent., 10: 207-32

Farrell, I. A. K.; Sweney. W. I.. 1972. Plant resistance to grass grub Costelytra zealandica" (Col. "Scarabaeidae). J. Resistance in pasture legumes. N.Z. II agric. Kes., 1.5: 904-8.

- $1974 \mathrm{a}$. Plant resistance to grass grub Costelyfra zealandica (Col. Scarabaeidae). JJ. Screening for resistance in grasses. Ibid., 17: 63-7.

- $1974 \mathrm{~b}$. Plant resistance to grass grub Costelyfra żeaIandica. III. Resistance in Lotus and Luoinus. Ibid., 17: 69-72.

Given, B. B., 1967. Biological control of wekds and insect pests in New Zealand. Mushi, '39 Suppl.: 17-22.

Kain, W. M., 1975. Population Dynamics and Pest Assessment Studies of Grass Grub (Costelytra zealandica (White) Melolonthinge) in the North Island of New Zealand. Ph.D. thesis, Lincoln College, University of Canterbury. 297 pp.

Kain, W. M.; Atkinson, D. S., 1970. A rational approach to grass grub control. Proc. 23rd N.Z. Weed \& Pest Control Conf.: 180-3. 
Kain, W. M.; Crabtree, R., 1972. Aerial application of an organophosphate insecticide for the control of grass grub. Proc. 25th N.Z. Weed \& Pest Control Conf.: 257-62.

Painter, R. H., 1951. Insect Resistance, in Crop Plants. Macmillan, New York.

Pottinger, R. P., 1975. Plant resistance to insect pests - a general review with reference to New Zealand grassland farming. Proc.N.Z. Grassld Ass., 37: 114-25.

Sutherland, 0. R. W.; Hillier, J. R., 1974. Olfactory 'response of Costelytra zealandica (Coleoptera: Melolonthinae) to roots of several pasture plants. N.Z. Il Zool., 1: 365-9. 